\title{
THE EFFECTS OF INNOVATION CULTURE AND LEARNING ORIENTATION ON ORGANIZATIONAL AGILITY
}

\author{
DOI: 10.17261/Pressacademia.2019.1077 \\ PAP-V.9-2019(24)-p.109-113
}

\section{Serdar Ozcan ${ }^{1}$}

${ }^{1}$ Çanakkale Onsekiz Mart University, Institute of Social Sciences, Çanakkale, Turkey. serdarozcan@kale.com.tr, ORCID: 0000-0002-2136-2049

\section{To cite this document}

Ozcan S., (2019). The effects of innovation culture and learning orientation on organizational agility. PressAcademia Procedia (PAP), V.9, p.109-113

Permemant link to this document: http://doi.org/10.17261/Pressacademia.2019.1077

Copyright: Published by PressAcademia and limited licenced re-use rights only.

\section{ABSTRACT}

Purpose- The main aim of this study is to determine the effects of innovation culture and learning orientation on organizational agility in terms of white collar employees.

Methodology- In order to achieve this aim, 150 white collar employees in a private organization operating in the manufacturing sector in Çanakkale were analyzed with the SPPS software. Totally 131 questionnaires were analyzed.

Findings- First, variables are tested to be reliable and valid. After that relationship between the variables was observed by performing regression analysis.

Conclusion- As a result of the analysis, it has been determined that innovation culture and learning orientation affects the organizational agility of white collar employees positively and significantly.

Keywords: Manufacturing sector, innovation culture, learning orientation, organizational agility, validity, regression. JEL Codes: M10, M14.

\section{YENILIK KÜLTÜRÜNÜN VE ÖĞRENME ODAKLILIĞIN ÖRGÜTSEL ATIKLIK ÜZERINDEKI ETKISi}

\section{ÖZET}

Amaç- Bu çalışmanın temel amacı, yenilik kültürü ve öğrenme odakııı̆̆ın örgütsel atiklik üzerindeki etkilerinin beyaz yakalı çalışanlar açısından belirlenmesidir.

Yöntem- Bu amaca ulaşmak için, Çanakkale'de üretim sektöründe faaliyet gösteren özel bir kuruluşta 150 beyaz yakalı çalışan SPPS yazııımı ile analiz edilmiştir. Toplam 131 anket dikkate alınarak analizler gerçekleştirilmiştir.

Bulgular- Öncelikle değişkenlerin güvenilir ve geçerli oldukları test edilmiştir. Devamında regresyon analizi yapılarak değişkenler arası ilişki gözlenmiştir.

Sonuç- Yapılan analizler sonucunda, yenilik kültürü ve öğrenme odaklılı̆ın beyaz yakalı çalışanların örgütsel atikliğini pozitif ve anlamlı bir şekilde etkilediği belirlenmiştir.

Anahtar Kelimeler: Üretim sektörü, yenilik kültürü, öğrenme odakılık, örgütsel atiklik, geçerlilik, regresyon.

JEL Kodları: M10, M14.

\section{GíRiş}

Başarılı kuruluşların iş dünyasında değişen pazar koşullarına uyum sağlayabilmeleri için bazı rekabet edebilme tekniklerini kullanması gerekmektedir. Bu tekniklerden biri de rekabeti arttırmak, müşteri odaklılığı sağlamak ve öngörülemeyen pazar koşullarına hakim olmak için gerekli bir bileşen olan "atiklik"'tir (Swafford vd., 2006: 171). Örgütsel atiklik; kuruluşun, potansiyel ihtiyaçları karşılayan çözümler sunmanın yanı sıra, beklenmeyen fırsatlara hızlı ve etkin bir şekilde yanıt verebilme yeteneğidir. Örgütsel atiklik, değişen pazarlara hızı bir şekilde cevap vererek, hem ürün hem de hizmet olarak müşterilerin istek ve ihtiyaçlarını karşılayarak, beklenmedik rekabetçi bir değişim ortamı içinde hayatta kalabilme ve büyüme kabiliyetidir. Ayrıca örgütsel atiklik, kuruluşun yüksek kalitede ve etkili performans üreterek hızlı ve tutarlı bir şekilde değişen ve parçalanmış bir küresel pazar ortamında rahatça çalışarak, kuruluşun ticari faaliyetlerdeki firsatları ve riskleri etkin bir şekilde yönetmesidir. Buna ek olarak örgütsel atiklik, kurumların kaynaklarını korumayı ve müşterilerin isteklerini zamanında gerçekleştirmeyi hedefleyen proaktif bir yönetim stratejisidir (Nafei, 2016: 273). 
Bu nedenle, örgütsel atikliğe etkisi olan bileşenleri tespit etmek önemlidir. Örgütsel atikliğin geliştirilmesi ve yaygınlaştırılmasından elde edilen faydalar; organizasyondaki süreçlerin iyileştirilmesi, gereksiz faaliyetlerin belirlenmesi, pazar payının artması, maliyetlerin kontrol edilebilmesi ve düşürülmesi nedeniyle organizasyonel verimliliğin artııılması ve bilgiye yatııım yapılmasının karşılığında değer elde edilmesi gibi çok sayıdadır (Moshki ve Teimouri, 2012: 63). Bu çalışma ile üretim sektöründe örgütsel atikliğe etki eden bazı bileşenlerin incelenmesi amaçlanmaktadır. Bu çalışmada bu bileşenler, yenilik kültürü ve öğrenme odaklılık olarak değerlendirilmiştir. Sonuç olarak, bu çalışma ile üretim firmalarının örgütsel atiklik seviyelerinin belirlenmesi ve yenilik kültürü ile öğrenme odaklılığının örgütsel atikliğe etkilerinin araştırııması ve böylece literatüre katkı sağlanması amaçlanmaktadır.

\section{LITERATÜR INCELEMESI}

\section{1. Örgütsel Atiklik}

Atiklik kavramının ortaya çıkması 1980' li yıllardaki Amerikan endüstrisinin durgunluk dönemine ve rekabet gücünü kaybetmesine dayanmaktadır. Bununla birlikte, örgütsel atiklik terimi ilk olarak 1991 yılında akademisyenler tarafından sunulan bir laccoca Ajansı raporunda kullanılmıştır (Kanani, 2016: 102). laccoca Ajansının ilk raporunun ardından, araştırmacılar atiklik kavramını keşfetmeye ve atiklik araştırmalarını üretim alanından daha geniş kapsamlı iş alanlarına genişletmeye çalışmışlardır. Böylece, atiklik kavramının operasyonlar ve iş stratejisi yönetimi, insan kaynakları yönetimi, tedarik zinciri yönetimi ve bilgi sistemleri gibi çeşitli disiplinlerde çekici bir konu haline geldiği görülmektedir (Thao, 2012: 13). Zhang ve Sharifi (2000) örgütsel atikliği, yanıt verebilirlik, yetkinlik, esneklik ve hız olarak etiketlenen boyutlar altında incelemiştir. Yanıt verebilirlik, değişiklikleri tanımlama, değişikliklere hızla yanıt verebilme ve değişikliklerden kurtulma yeteneğini ifade eder. Yetkinlik, bir kuruluşun verimlilik, yeterlilik ve etkinlik ile ilgili amaç ve hedeflerine ulaşmasını sağlayan yetenekleri. Esneklik, ürün hacim esnekliği, örgütsel konuların esnekliği ve insan esnekliği kabiliyetini ifade eder. Son boyut olan hız ise en kısa sürede görevleri ve operasyonları gerçekleştirme yeteneğini ifade eder. Bu nedenle, atikliğin bileşenleri aracılığıyla, kuruluşların kendilerini mevcut teknolojilere ve öngörülemeyen çalışma koşullarına adapte edebildikleri söylenebilir. Ayrıca, atikliğin boyutları, kuruluşların rekabetçi bir ortamda hayatta kalmalarını, istikrarsız pazarlara ve müşteri taleplerine hızlı yanıt vermelerini sağlar (Kanten vd., 2017: 699).

Atiklik, kurumlar için çevresel değişimleri hızlı bir şekilde anlamalarını sağlayan bir rekabet avantajıdır. Atik organizasyonlar değişimlere adapte olmanın ötesine geçmekte ve ilerlemeyi, başarıyı ve hayatta kalmayı başarmak için potansiyel fırsatları aramaktadırlar (Moshki ve Teimouri, 2013: 63).

\subsection{Yenilik Kültürü ve Öğrenme Odaklılık}

Yaşamını sürdürebilmesi için her kuruluşun beslemesi gereken temel süreçlerinden biri olarak yenilik, son zamanlarda daha fazla önem kazanmıştır. Bir örgütteki yenilik, değişime cevap vermenin ötesine geçer diğer örgütlerin cevap vermesi gereken ortamda değişiklik yaratarak sürdürülebilir rekabet avantajı haline gelebilir (Coffman, 2009:1). Yenilik kültürü ayrıca, insanların ifadelerini, geçmişlerini, inançlarını, fikirlerini ve davranışlarını ifade etmektedir. Yenilik kültürü hala çok yaygın olmadığı için onu yaratmak o kadar kolay değildir. Çünkü yenilik kültürünü yaratmak için gerekli özellikler hala kurumlarda elzem bir özellik olarak görülmemektedir (Morris, 2007: 3). Yenilik kültürünün ilk yasası güvendir. Eğer güven oluşturulamazsa ya da oluşturulmak istenilmezse, yenilik kültüründen bahsetmek yanlış olacaktır. İlk adımı atmak ve güvensizliği azaltmak yönetimin sorumluluğundadır (Coffman:3). Güçlü yenilik kültürüne sahip şirketlerdeki çalışanlar, tüm çalışanların katkısına değer verir, kendilerini yaratıcı ve yenilikçi olarak görür ve belirsizliği risk olarak değil bir fırsat olarak görürler (Dobni, 2008: 548549).

Öğrenme Odaklılık; "bir örgütün bilgi oluşturabilme ve kullanabilme eğilimine yön veren, örgüt kültürü kümesinin” oluşması olarak açıklanmaktadır. Kısaca öğrenme odaklılık, işletmelerin bir örgüt olarak bilgi ile olan ilişkilerini ifade etmek için kullanılan bir kavramdır (Adıgüzel, 2018: 412). Örgütsel öğrenme kavramı, son birkaç yılda hem araştırma alanında hem de uygulayıcılar arasında zamanla önem kazanmıştır. Çünkü kurumların ve kurumların faaliyetlerinin daha iyi anlaşılmasına katkıda bulunmaktadır (Chiva,2004: 233). Bilgi çağı kuruluşlarının rekabet gereksinimleri daha küresel, daha müşteri odaklı, daha esnek, daha öğrenmeye odaklı ve ekip çalışmasına daha bağımlıdır. Öğrenen örgüt olma eğiliminde olan bu ihtiyaçlar, duygusal, entelektüel ve fiziksel enerjilerini organizasyonun başarısı için birleştiren ve yüksek bir bağlılığa sahip olan insanları gerektirmektedir. Araştırmalar, yüksek bağlılığa sahip çalışanların, onlardan bekleneni elde etmek ve kurumsal hedeflere ulaşmak için daha fazla çaba sarf ettiğini göstermektedir(Atak ve Erturgut, 2010: 3473).

\subsection{Araştırma Modeli ve Hipotezler}

Literatürde Kanten vd (2016) ve Triaa vd (2016)'nin çalışmalarında; müşteri odaklılık personel güçlendirme, dinamik yetenekler, bütünleştirme, koordinasyon ve yenilik kültürü gibi faktörlerin örgütsel atikliği etkilediği belirtilmektedir. Bu bağlamda araştırmada, örgütsel faktörler kapsamında yenilik kültürünün ve öğrenme odaklılığın örgütsel atikliği etkileyeceği varsayılmaktadır. Bu doğrultuda aşağıdaki araştırma modeli ve hipotezleri geliştirilmiştir:

H1: Yenilik Kültürü Örgütsel Atikliği anlamlı yönde etkilemektedir.

H2: Sürekli Öğrenme Örgütsel Atikliği anlamlı yönde etkilemektedir.

H3: Ekip Öğrenimi ve Gömülü Sistemler Örgütsel Atikliği anlamlı yöndeetkilemektedir.

H4: Liderlik Örgütsel Atikliği anlamlı yönde etkilemektedir.

H5: Güçlendirme Örgütsel Atikliği anlamlı yönde etkilemektedir. 
Şekil 1: Araştırmanın Modeli

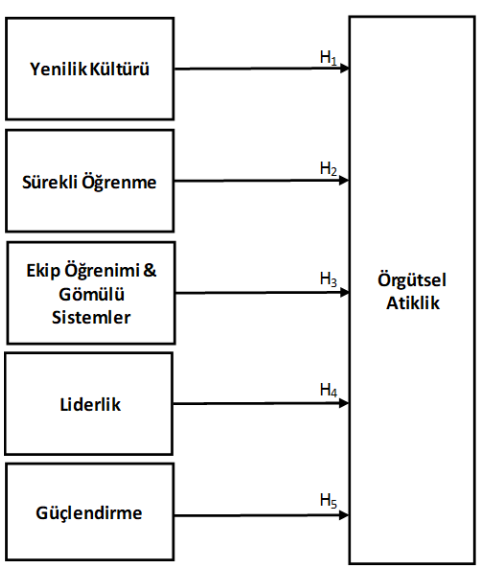

\section{YÖNTEM}

Araştırmanın amacına ulaşmak için intiyaç duyulan veriler, Çanakkale ilinde bulunan bir üretim şirketinin 131 beyaz yakalı çalışanından anket yöntemi ile toplanmışır. Anket formunun birinci bölümünde araştırmanın modelini oluşturan değişkenleri ölçmeye dayalı sorular yer almaktadır. İkinci bölümde ise, demografik özelliklere ve kuruluşta kullanılan sistemleri belirlemeye yönelik sorular yer almaktadır. Örgütsel atiklik; Spitzer'in (2007) araştırmasından alınan 19 soru, öğrenme odakııık; Basım vd.(2007) araştırmasından alınan 38 soru ve yenilik kültürü ölçeği ise, Dobni'nin (2008) araştırmasından 5 soru ile ölçülmüştür. Araştırma kapsamında kullanı firma itibarı ve memnuniyet ölçekleri $5^{\prime} l i$ likert ölçeğine (Kesinlikle katılmıyorum (1), Katılmıyorum (2), Ne Katılıyorum Ne Katılmıyorum (3), Katılıyorum (4), Kesinlikle Katılıyorum) göre düzenlenmiştir.

\section{BULGULAR}

\subsection{Demografik Bulgular}

Araştırmaya katılanlar demografik açıdan incelendiğinde, \%30,4'ü kadın, \%69,6'sı erkek. \%22,5'i lise, \%15,3'ü ön lisans, \%45,9'u lisans ve \%16,2'si yüksek lisans mezunudur. Çalışanların \%2,7'si 18-25 yaş aralığında, \%20'si 26-33 yaş aralığında, \%40,9'u 34-41 yaş aralığında, \%31,8'i 42-49 yaş aralığında ve \%4,5'i de 50 ve üzeri yaşlardadır. Görev dağılımları olarak \%2,7'si üretim mühendisi, \%6,8'i formen, \%28,8'i Yönetici, $\% 17,8^{\prime}$ i teknisyen, \%19,2'si sorumlu,\%4,1’i müdür, \%4,1'i tekniker, \%1,4'ü direktör ve \%15,1'i uzman ve uzman yardımcısı ünvanlarına göre dağılmışlardır. Çalışma sürelerine bakıldığında çalışanların \%8,7'si 1 yıldır, \%5,8'i 2-3 yıldır, \%5,8'i 4-6 yıldır,\%13,5'i 7-9 yıldır ve \%66,3'ü 10 yıl ve üzeri yıldır aynı işletmede çalıştıkları sonucuna ulaşılmıştır. Katılımcıların demografik özelliklerine ilişkin Frekans Analizi sonuçları Tablo 1 'de sunulmuştur.

\section{Tablo 1: Cevaplayıcıların Demografik Özellikleri}

\begin{tabular}{|c|c|c|c|c|c|c|c|c|}
\hline Görev & $\mathrm{n}$ & Yüzde & Cinsiyet & $\mathrm{n}$ & Yüzde & Mezuniyet & $\mathrm{n}$ & Yüzde \\
\hline Direktör & 1 & $1,40 \%$ & Kadın & 34 & $30,40 \%$ & Lise & 25 & $22,50 \%$ \\
\hline Müdür & 3 & $4,10 \%$ & Erkek & 78 & $69,60 \%$ & Önlisans & 17 & $15,30 \%$ \\
\hline Yönetici & 21 & $28,80 \%$ & Yaş & $\mathrm{n}$ & Yüzde & Lisans & 51 & $45,90 \%$ \\
\hline Sorumlu & 14 & $19,20 \%$ & $18-25$ & 3 & $2,70 \%$ & Lisansüstü & 18 & $16,20 \%$ \\
\hline Uzman-Uzman Yardımcısı & 11 & $15,10 \%$ & $26-33$ & 22 & $20,00 \%$ & 5-Kurumsal Kaynak Planlaması var & 34 & $32,40 \%$ \\
\hline Üretim Mühendisi & 2 & $2,70 \%$ & $34-41$ & 45 & $40,90 \%$ & 6-Tedarik Zinciri Uygulaması var & 69 & $65,70 \%$ \\
\hline Teknisyen & 13 & $17,80 \%$ & $42-49$ & 35 & $31,80 \%$ & 7-Müşteri ilişkileri Uygulaması var & 54 & $51,40 \%$ \\
\hline Tekniker & 3 & $4,10 \%$ & 50 ve üzeri & 5 & $4,50 \%$ & 8-E-Ticaret Uygulaması var & 7 & $6,70 \%$ \\
\hline Formen & 5 & $6,80 \%$ & & & & 9-İşZZekası var & 19 & $18,10 \%$ \\
\hline & & & & & & 10-Bilgi Yönetimi Uygulaması var & 28 & $26,70 \%$ \\
\hline
\end{tabular}

\subsection{Geçerlilik ve Güvenilirlik Analizi}

Çalışmada kullanılan ölçeklerinin yapısal geçerlilikleri ve güvenilirlik düzeyleri test edilmiştir. Yenilik kültürü, öğrenme odakılık ve örgütsel atiklik değişkenlerine ait verilere uygulanan keşfedici faktör ve güvenilirlik analizlerine ilişkin bulgular Tablo 2'de özet olarak sunulmuştur. 
Tablo 2: Faktör ve Güvenirlilik Analizi

\begin{tabular}{|c|c|c|c|c|c|}
\hline $\begin{array}{l}\text { Yenilik Kültürü } \\
\text { (5 soru için) } \\
\text { KMO: .718 } \\
\text { Varyans: \%50,2 }\end{array}$ & $\begin{array}{l}\text { Cron. } \\
\text { Alfa } \\
.747\end{array}$ & $\begin{array}{l}\text { Öğrenme Odaklılık } \\
\text { (kalan } 20 \text { soru için) } \\
\text { KMO: .864 } \\
\text { Varyans: \%63 }\end{array}$ & $\begin{array}{l}\text { Cron. } \\
\text { Alfa }\end{array}$ & $\begin{array}{l}\text { Örgütsel Atiklik } \\
\text { (kalan } 11 \text { soru için) } \\
\text { KMO: .824 } \\
\text { Varyans: \%62 }\end{array}$ & $\begin{array}{l}\text { Cron. } \\
\text { Alfa }\end{array}$ \\
\hline & & $\begin{array}{l}\text { 1. Boyut: Sürekli } \\
\text { Öğrenme }\end{array}$ & .855 & 1. Boyut: Hızlılık & .785 \\
\hline & & $\begin{array}{l}\text { 2. Boyut: Ekip Öğrenimi } \\
\text { \&Gömülü Sistemler }\end{array}$ & .828 & $\begin{array}{l}\text { 2. Boyut: Cevap } \\
\text { Verme }\end{array}$ & .741 \\
\hline & & 3. Boyut: Liderlik & .853 & 3. Boyut: Yetkinlik & .756 \\
\hline & & 4. Boyut: Güçlendirme & .832 & & \\
\hline
\end{tabular}

Tanımlayıcı analizler kapsamında yenilik kültürü, öğrenme odaklıık ve örgütsel atiklik ile ilgili ortalamalar, standart sapmalar ve korelasyonlar yapılmıştır. Sonuçlar Tablo 3'te verilmiştir. Korelasyon matrisine göre, çalışanların yenilik kültürlerinin ve öğrenme odaklarının artmasının örgütsel atikliği arttırması beklenmektedir.

Tablo 3: Ortalama, Standart Sapma ve Korelasyon Değerleri

\begin{tabular}{|l|r|c|c|c|c|}
\hline${ }^{* *} \mathbf{p}<0.001$ & Ortalama & Standart Sapma & $\mathbf{1}$ & $\mathbf{2}$ & $\mathbf{3}$ \\
\hline YENILiK KÜLTÜRÜ & 3,3298 & 0,57428 & 1 & & \\
\hline ÖĞRENME ODAKLILIK & 3,2607 & 0,52919 & $.599^{* *}$ & 1 & \\
\hline ÖRGÜTSEL ATIKLIK & 3,3518 & 0,52821 & $.525^{* *}$ & $.728^{* *}$ & 1 \\
\hline
\end{tabular}

\subsection{Regresyon Analizi}

Araştırmada ele alınan değişkenler arasındaki ilişki bir model yardımı ile ele alınmıştır. Model, regresyon analizi ile test edilmiştir. Gerçekleştirilen analiz sonucunda, yenilik kültürü, sürekli öğrenme, ekip öğrenimi ve gömülü sistemler, liderlik ve güçlendirmenin örgütsel atikliği olumlu yönde ve anlamlı bir şekilde etkilediği tespit edilmiştir. Yapılan analizler aşağıdaki tabloda sunulmuştur.

Tablo 4: Firma İtibarının Müşteri Memnuniyeti Üzerindeki Etkisi

\begin{tabular}{|c|c|c|c|c|c|}
\hline $\begin{array}{c}\text { Bağımsız } \\
\text { Değişkenler }\end{array}$ & $\begin{array}{c}\text { Bağımlı } \\
\text { Değişken }\end{array}$ & $\mathbf{R}^{\mathbf{2}}$ & $\mathbf{b}$ & $\mathbf{F}$ & $\mathbf{p}$ \\
\hline Yenilik Kültürü & Örgütsel Atiklik & .525 & .483 & 49.008 & .000 \\
\hline Sürekli Öğrenme & Örgütsel Atiklik & .559 & .428 & 58.556 & .000 \\
\hline Ekip Öğrenimi\&Gömülü Sistemler & Örgütsel Atiklik & .542 & .431 & 53.608 & .000 \\
\hline Liderlik & Örgütsel Atiklik & .659 & .569 & 98.773 & .000 \\
\hline Güçlendirme & Örgütsel Atiklik & .539 & .377 & 52.865 & .000 \\
\hline
\end{tabular}

*0,001'a göre anlamlıdır.

\section{SONUÇ VE ÖNERILER}

Araştırma sonuçları, Yenilik kültürü ve öğrenme odaklılığın çalışanların örgütsel atikliği algısı üzerinde olumlu ve anlamlı yönde bir etkisinin olduğunu göstermiştir. Bu bağlamda yenilik kültürü, sürekli öğrenme, ekip öğrenimi ve gömülü sistemler, liderlik ve güçlendirme boyutları olumlu ve anlamlı bir şekilde örgütsel atikliği etkilemektedir. Böylece tüm hipotezlerin geçerliliği kanıtlanmıştır. Yenilik kültürü \%52 ile en az etkiye sahip çıkmışır. Bu kurum tarafından planlanan ve kısmen faaliyete geçirilen dijital dönüşümlerin tamamlanmasından sonra bu etkinin daha yukarılara çıkabileceği öngörülebilir. Öte yandan, çalışanların alınan kararlara dahil edilmesi, inisiyatif almalarının sağlanması ve başarıı ekiplerin ödüllendirilmesi konusunda yapılacak iyileştirmelerle örgütsel atikliğe nispeten daha az etkisi görülen ekip öğrenimi\&gömülü sistemler ile güçlendirme boyutlarının etkilerinin artabileceği öngörülebilir.

Ayrıca, öğrenme odaklıı̆̆ı çıkarılan 2 boyutunu ele alırsak, bu kurumda çalışanların fikir ve önerilerine daha fazla önem verilmesi, iş ve aile yaşamları arasında denge kurmalarına müsaade edilmesi, birbirleri arasındaki işbirliklerinin arttırılması, birbirlerini saygılı bir biçimde dinleyip, birbirlerini anlamaları için zaman ayırmaları durumlarında kurumun örgütsel atikliğinin artacağı da öngörülmektedir. 
Yenilik kültürünün bu araştırmada ele alınmayan diğer 6 boyutunu da araştırmalarına dahil edip, yenilik külttürünün tüm boyutlarının örgütsel atiklik üzerindeki etkilerini incelenebilir. Aynı üretim sektöründeki daha fazla kuruluşu araştırmaya dahil edip, daha geniş ve farklı örneklemlerde yenilik kültürü ve öğrenme odaklılı̆ın örgütsel atikliğe etkileri sektörel olarak incelenebilir.

\section{KAYNAKÇA}

Adıgüzel Z. (2018). Öğrenme Odaklılığının Hizmet Sektöründe Bulunan Çalışanlar Üzerindeki Etkileriyle Birlikte Lider Etkililiğinin Ara Değişken Etkisinin İncelenmesi. Business\&Management Studies: An International Journal. Vol.:6, Issue:2, p. 410-429.

Atak M., Erturgut R.,(2010). An Empirical Analysis on The Relation between learning organization ans organizational commitment. ScienceDirect. p. 3473

Basim H.N., Sesen H. ve Korkmazyürek H.,(2007). A Turkish Translation, Validatity and Reliability Study of the Dimensions of the Learning Organization Questionnaire. World Applied Sciences Journal 2(4), p. 368-374.

Chiva-Gomez R.,(2004). The Facilitating Factors For Organizational Learning In The Ceramic Sector. Aricle in Human Development International. p. 233.

Coffman B. (2009). Building the Innovation Culture. innovationlabs:

https://www.innovationlabs.com/Building\%20the\%20Innovation\%20Culture.pdf. p.1,3.

Dobni C.B, (2008). Measuring Innovation Culture in Organizations: The development of a generalized innovation culture construct using exploratory factor analysis. Emeraldinsight. p. 543, 548, 549.

Kanani, N. (2016). Analysis of Factors Affecting Organizational Agility. Singaporean Journal of Business Economics and Management Studies,vol.5,no.2, p.102-108.

Kanten P., Kanten S., Keçeli M. ve Zaimoğlu Z.(2017). The Antecedents Of Organizational Agility: Organizational Structure, Dynamic Capabilities And Customer Orientation. Global Business Research Congress(GBRC), May 24-25, 2017, Istanbul Turkey. P.698.

Nafei W.A. (2016). The Effect of Organizational Agility on Quality of Work Life: A Study on Commercial Banks in Egypt. International Journal of Business and Management, vol.11, no.6, p .271-285.

Morris, L. (2007). Creating the Innovation Culture: Geniuses, Champions and Leaders. An InnovationLabs White Paper. https://www.innovationlabs.com/CreatingInnovationCulture.pdf. p.3.

Moshki,M.K, Teimouri H. (2013). A survey on the level of Organization Agility and proposition of a Comprehensive model (the case of Nir Pars Company). International Journal of Human Resource Studies, Vol.3 no.3, p:63.

Spitzer, D.R. (2007). Transforming Performance Measurement: Rethinking the Way We Measure and Drive Organizational Success. American Management Assocation, New York.

Swafford, P.M., Ghosh, S., Murthy, N. (2006). The Antecedents of Supply Chain Agility of a Firm: Scale Development and Model Testing. Journal of Operations management, vol.24, p. 170-188.

Thao, T.P. (2012). Enterprise Systems and Organisational Agility: Developing and Exploring a Causal Model. Doctor of Philosophy, School of Business Information Technology and Logistics Business College, RMIT University. p.13.

Wafa Triaa, Lilia Gzara, Hervé Verjus (2016). Organizational agility key factors for dynamic business process management. HAL. p. 3.

Zhang Z., Sharifi, H. (2000). A Methodology for Achieving Agility in Manufacturing Organisations. International Journal of Operations \& Production Management, vol.20, no.4, p .496-513. 